provided palmar digital branches to the radial side of the index finger and the ulnar side of the thumb, without any contribution to the SPA. However, the radial side of the thumb was supplied by a branch from the deep palmar arch. The superficial branch of the ulnar artery gave origin to three common palmar digital arteries to supply the contiguous sides of the index, middle, ring and little fingers. It also provided origin to a digital branch to the ulnar side of the little finger.

The superficial arteries of the hand formed several diversified patterns that permitted into well-defined categories. About one-third of the SPA is formed by the ulnar artery alone; a further third is completed by the superficial palmar branch of the radial artery and a third either by the arteria radialis indicis or by the princeps pollicis or by the median artery. ${ }^{[1]}$ A classic type of SPA in which the superficial branch of the radial artery joins the superficial branch of the ulnar artery is found only in $34.5 \%$ of the cases. ${ }^{[1,2]}$ There are many reports regarding formation of SPA. In a study by Coleman et al., the complete arch was found in $78.5 \%$ of the cases and incomplete arch in the remaining $21.5 \%$, and this formed a major underlying factor in the aetiology of digital ischaemia. ${ }^{[3]}$ Ikeda et al. conducted stereoscopic arteriography of 220 cadaver hands and reported complete SPA in $96.4 \%$ of the cases, and only $3.6 \%$ had an incomplete arch. ${ }^{[4]}$ Gellman et al. showed a complete SPA in $84.4 \%{ }^{[5]}$ and Al Turk and Metcalf reported complete SPA in $84 \%$ of the cases. ${ }^{[6]}$ Knowledge of the anatomical variations of the arterial

\title{
Variant formation and distribution of the superficial palmar arch
}

Sir,

The anastomoses between radial and ulnar arteries in the palm play a significant role in diseases of the palm through collateral circulation. During routine dissection of the left upper limb of a 45-year-old male cadaver, we observed the superficial palmar arch (SPA) formed exclusively by the superficial branch of the ulnar artery [Figure 1]. The superficial palmar branch of the radial artery entered the hand through the thenar muscles and

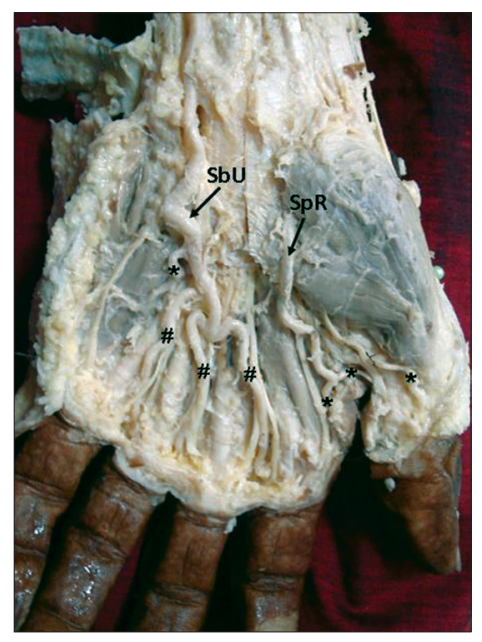

Figure 1: Dissection of the left palm showing the superficial palmar arch formed solely by the superficial branch of the ulnar artery. \#Common palmar digital arteries; *Proper palmar digital branches; SbU, superficial branch of the ulnar artery; SpR, Superficial palmar branch of the radial artery 
pattern of the hand is crucial for safe and successful hand surgery. The hand surgeon should keep in mind this kind of variation while performing surgical procedures such as, arterial repairs, vascular graft applications and free and/or pedicled flaps. While harvesting the radial artery for use as arterial by-pass conduits or while harvesting the free Radial Forearm Flap, the need to look specifically for variation in collateral circulation, like presence of incomplete SPA ${ }^{[7]}$ is a must. Currently, the methods of assessing hand circulation include the modified Allen test, Doppler ultrasonography and photoplethysmography. Doppler study is a useful tool in pre-operative screening for radial artery harvesting for myocardial revascularisation. ${ }^{[8]}$

SPA is an anastomosis, fed mainly by the ulnar artery. When the ulnar artery is occluded, the viability of the structures in the palm supplied by the ulnar artery depends on the efficacy of the collateral circulation. In the present case, there was no anastomosis between the ulnar artery and the radial or median or interosseous arteries. Thus, in ulnar artery occlusion in cases like ours, there will be no collateral flow of blood to meet the metabolic demands of the palmar tissue, and this will result in acute ischaemia, manifested by claudications, rest pain and/or gangrene.

\section{Srinivasa Rao, Venkata Ramana Vollala, Narendra Pamidi, Somayaji Nagabhooshana, Bhagath Kumar Potu}

Department of Anatomy, Manipal University, Manipal, India

Address for correspondence: Dr. Venkata Ramana Vollala, Melaka Manipal Medical College, (Manipal Campus), Manipal University, Manipal - 576104, India. E-mail: ramana.anat@gmail.com

\section{REFERENCES}

DOI: 10.4103/0970-0358.63942

1. Willams PL, Bannister LG, Berry MM. Gray's Anatomy. $38^{\text {th }}$ ed. New York: Churchill Livingstone; 2000. p. 1544.

2. Moore KL, Dalley AF. Clinically Oriented Anatomy. $10^{\text {th }}$ ed. Philadelphia: Lippincott, Williams and Wilkins; 1999. p. 751.

3. Coleman SS, Anson BJ. Arterial patterns in the hand based upon a study of 650 specimens. Surg Gynecol Obstet 1961;113:409-24.

4. Ikeda A, Ugawa A, Kazihara Y, Hamada N. Arterial patterns in the hand based on a three-dimensional analysis of 220 cadaver hands. J Hand Surg Am 1988;13:501-9.

5. Gellman H, Botte MJ, Shankwiler J, Gelberman RH. Arterial patterns of the deep and superficial palmar arches. Clin Orthop Relat Res 2001;383:41-6.

6. Al-Turk M, Metcalf WK. A study of the superficial palmar arteries using the Doppler Ultrasonic Flowmeter. J Anat 1984;138:27-32.

7. Ruengsakulrach P, Brooks M, Hare DL, Gordon I, Buxton BF. Preoperative assessment of hand circulation by means of Doppler ultrasonography and the modified Allen test. J Thorac Cardiovasc
Surg 2001;121:526-31.

8. Pola P, Serricchio M, Flore R, Manasse E, Favuzzi A, Possati GF. Safe removal of the radial artery for myocardial revascularization: A Doppler study to prevent ischemic complications to the hand. J Thorac Cardiovasc Surg 1996;112:737-44. 